\title{
DESENVOLVIMENTO DA AMAZÔNIA: A COMPLEXA RELAÇÃO ENTRE O NACIONAL E O REGIONAL
}

E. C. SILVA
$\begin{gathered}\text { Programa de Pós-graduação em História (UFU) } \\ \text { coimbraelias@hotmail.com }\end{gathered}$
Artigo submetido em abril/2014 e aceito em outubro/2014
DOI: $10.15628 /$ holos.2014.2101

\section{RESUMO}

Este artigo busca refletir acerca da Região Amazônica, bem como dos projetos políticos e econômicos destinados a planejar e a desenvolver essa mesma região. Existe, portanto, a preocupação com a própria ideia de "região", a qual nos conduziu a uma breve discussão desse conceito. Discussão essa que nos autoriza a perguntar pelas razões políticas envolvidas no ato divisório da regionalização e, consequentemente, nos permite pensar sobre quais deveriam ser as perspectivas geoeconômicas e geopolíticas acerca dessa região. Assim, tendo em conta a complexidade de sua natureza, tanto quanto de sua sociedade, mas, principalmente a complexidade do contexto atual, buscamos entender qual a melhor alternativa para a manutenção desse vasto seguimento do Brasil

PALAVRAS-CHAVE: Região, Escala, Desenvolvimento, Sustentabilidade.

\section{DEVELOPMENT OF THE AMAZON: THE COMPLEX RELATIONSHIP BETWEEN THE NATIONAL AND THE REGIONAL}

\begin{abstract}
This article aims to reflect on the Amazon region, and about the political and economic projects to plan and develop this same region. Therefore, we have a concern with this very idea of "region", which led us to a brief discussion of this concept. Discussion that authorized us wonder about the political reasons involved in divisive act of regionalization and hence allows us to think about
\end{abstract}

what should be the geo-economic and geopolitical perspectives about this region. Thus, considering the complexity of his nature, as much as of their society but primarily the complexity of the current context, we seek to understand what the best alternative for the maintenance of this wide slice of Brazil.

KEYWORDS: Region, Scale, Development, Sustainability. 


\section{INTRODUÇÃO}

O papel da Amazônia, no cenário político e econômico brasileiro, tem passado por constantes transformações ao longo de nossa história. Desde as "visões do paraíso" dos colonizadores portugueses, passando pelo "Inferno Verde" de Alberto Rangel e Euclides da Cunha, até a concepção de reserva estratégica (que resultou nas políticas de Planejamento Regional), essa imensa porção do Brasil, com mais de 5.000 .000 de $\mathrm{Km}^{2}$ recebeu olhares e sofreu práticas as mais diversas. $O$ essencial, porém, permanece uma questão não equacionada: aquele território ainda em construção é uma parte do território nacional, mas cuja função (ou "vocação") carece de um delineamento preciso.

Num primeiro momento e por tratar-se, o presente texto, dum trabalho exclusivamente teórico, buscamos aqui problematizar a ideia de Região Amazônica como uma entidade com forma e conteúdo unívocos. Ao mesmo tempo em que apontamos as nuances sociais e culturais de um espaço cujo viés econômico parece estar mais evidente nas ações do estado, até pelo menos a última década do século XX.

Com essa problematização, esperamos atingir o cerne da "questão regional" em torno dessa entidade: a Amazônia, ou seja, essa "divisão" (da qual advém a entidade) é imposta e imposta com objetivo específicos. Assim, compreendidos os contornos políticos do problema divisório, trataremos dos diversos projetos para aquela região.

Nesse sentido buscaremos destacar a importância da Amazônia no contexto atual e, deste modo, a possibilidade de um diálogo entre o Nacional e o Regional, no âmbito de um projeto de sociedade (de cunho antimoderno ${ }^{1}$ ) que tem sido, ultimamente, valorizado. Me refiro ao controvertido paradigma da Sustentabilidade. Projeto esse que, sem extinguir por completo, minimiza a hegemonia da tradicionalíssima concepção de um "vazio demográfico", no tocante à Amazônia.

\section{A REGIÃO AMAZÔNICA.}

Quando pensada em termos históricos, desde a invasão portuguesa no séc. XVII, a Floresta Amazônica demonstra ter sido ocupada, a princípio, com o objetivo de explorar as drogas do sertão: "[...] o cravo, a canela, a castanha, a salsaparrilha e sobretudo o cacau" (PRADO JR., 1996, p. 211), com auxílio do trabalho dos indígenas - amealhados pelos jesuítas e carmelitas. A princípio, a demanda européia por essas especiarias (ou drogas), exigiu dos portugueses - como em várias outras ocasiões - uma estratégia geopolítica de combate à concorrência na extração dos produtos florestais (PRADO JR., 1998).

Foi com esse intuito que Francisco Caldeira de Castelo Branco, o Capitão-mor da Capitania do Rio Grande do Norte, ordenou a edificação do "Forte do Presépio de Belém", em 12 de janeiro de 1616 (BARRETO, 1958, p. 33-34). Depois disso, apenas no final do séc. XIX e por causa do látex - a matéria-prima da borracha -, o qual é extraído duma árvore nativa denominada seringueira,

\footnotetext{
${ }^{1}$ No sentido em que os historiadores tendem a ressaltar os limites da realização dos ideais da modernidade, o termo "antimoderno" surge como uma oposição (até mesmo dialética) ou então como um movimento, direcionamento (etc.) reacionário (CRUZ, 2011).
} 
haveria um afluxo considerável de pessoas àquela região. Aliás, é importante refletir aqui acerca desse conceito: Região, considerando sua conotação original na Geografia Clássica. Detenhamonos, por um momento, nesse ponto.

O conceito de Região Natural, de La Blache, parece ter tido como origem o mesmo termo termo esse, porém, geológico - que o geógrafo francês encontrou em Lyell (GOMES, 2003, p. 55). Então, a partir de 1908 - ano em que Gallois publica Régions Naturelles et Noms de Pays - esse discípulo de La Blache (Gallois) coloca a questão de que existe uma relação muito forte entre o ambiente físico e uma determinada comunidade; relação essa, constituída historicamente. Assim, poderíamos qualificar desse mesmo modo a relação que ocorre na região amazônica entre sua população (esparsa) e uma área que é mais do que oito vezes a França (o país de La Blache)? Aliás, de qual população, "exatamente", se trata? Outra questão: como falar de uma relação historicamente constituída se não estamos nos referindo à população autóctone amazônica (essa sim, estreitamente ligada ao seu ambiente)?

Essa "população regional" - no sentido de que há uma relação estreita entre o ambiente físico e a comunidade - deveria ser, por conseguinte, os próprios indígenas; embora Marcio de Castro (2007) assegure que, na Amazônia, tanto a população rural quanto a urbana possuem estratégias de sobrevivência apropriadas para a região e, portanto, estão habituadas ao meio. Por outro lado, quer nos parecer que esse autor se refere aos caboclos, mais do que aos operários (por exemplo) desta ou daquela fábrica de eletrônicos, na Zona Franca de Manaus.

De qualquer forma, o termo, ou melhor, o conceito de "Região", talvez pudesse ser aplicado à Amazônia no caso de atender a algum outro conteúdo que não aquele da Geografia Clássica. Talvez sequer o conteúdo defendido pela Nova Geografia, ou seja, aquele de Região Homogênea (GOMES, 2003, p. 63) poderia ser aplicado aí. Mesmo que fosse possível excluir os grupos humanos, por completo, ao longo da análise estatística (pressuposta pela caracterização da homogeneidade). O fato é que fragmentação do Brasil em regiões ocorreu independentemente das várias teorias sobre o termo; e a Amazônia representa um desses fragmentos do espaço da nação.

Porém, a Amazônia não é um todo, mas antes, a soma de partes. Chamemos soma, pois não é possível perceber, nesse caso, a ensambladura, a organicidade própria do Sistema que justificaria a noção clássica de Região: “[...] enquanto podemos conceber uma soma como sendo composta gradualmente, um sistema, enquanto total de partes com suas inter-relações, tem de ser concebido como constituído instantaneamente." (BERTALANFFY, 1973, p. 83). A Amazônica, deste modo, não é um grande organismo, uma gigantesca célula com mitocôndrias e cloroplastos funcionando num mesmo sentido, para administrar sua vida. Ela é antes um agregado de ecossistemas ${ }^{2}$ ocupados por agregados de grupos humanos parcamente tangidos por um ator centralizado: o Estado Nacional. Neste caso, a questão que deveríamos nos fazer é: quais intenções repousam por trás dessa construção discursiva e desse agregado.

Seguindo desse ponto, é lícito pensarmos que, constituída em sua soberania, a administração pública, arbitrariamente, traçou as fronteiras da Amazônia, em torno das quais se localiza o fora:

\footnotetext{
2 “[...] A própria floresta, como vimos, é um conjunto de florestas muito diferentes entre si: florestas de terras secas, de várzeas, mangues, igapós, além das áreas de transição" (CASTRO, 2007, p. 24).
} 
A regio e as suas fronteiras (fines) não passam do vestígio apagado do acto de autoridade que consiste em circunscrever a região, o território (que também se diz fines), em impor a definição (outro sentido de finis) legítima. Conhecida e reconhecida, das fronteiras e do território, em suma, o princípio de di-visão legítima do mundo social. (BOURDIEU, 1998, p. 114)

O fora e o dentro, ou melhor, esse um eufemismo para "o estrangeiro e o conterrâneo" (ou o nativo etc), é um exemplo da "antítese assimétrica" - para lançar mão da terminologia de Koselleck (2006) - que se encontra no centro duma gramática das fronteiras. Gramática essa que, como qualquer outra, serve a um propósito deontológico, posto que, se ela regula, se ela normaliza - e sua função é mesmo essa -, regula com objetivos mais do que meramente formais ou casuais. Entre esses objetivos não declarados está, justamente, a geográfica "di-visão": que está no fundamento e na fundação dessa regionalização que temos, criticamente, apontado aqui.

Atentemos, ademais, para o fato de que não se trata de uma reivindicação - a nosso ver, legítima - da possível (ou desejável) "identidade amazonense", mas antes, duma imposição (de cima para baixo) "divisória". Imposição que, entretanto e mesmo eventualmente, acaba resultando em uma apropriação local - e, via de regra, elitista - dessa divisão, na forma de um discurso identitário; um discurso artificial e artificioso: “[...] o nacionalismo e o Estado encamparam as associações de parentesco de vizinhança e da terra natal, para territórios e populações de dimensão e escala tais, que as transformaram em metáforas." (HOBSBAWM, 2003, p. 212).

As verdadeiras identidades, gestadas historicamente e no seio das comunidades ribeirinhas, por exemplo, acabam sendo "sobrescritas" por essa metáfora (que é uma ideologia) de Região Amazônica. Esse, enfim, é o sentido último do "agregado" para o qual chamamos a atenção anteriormente.

\section{A NECESSIDADE DE UM PROJETO}

Fechado assim esse necessário parêntese epistemológico de geografia e voltando agora à chamada "Região Amazônica". Vínhamos dizendo que houve uma migração considerável a essa mesma região, em consequência da exploração de um produto primário: o látex - cuja importância, no contexto da economia brasileira daquela época, cresceu subitamente. Esses migrantes, na maior parte nordestinos ${ }^{3}$, distinguem-se um pouco, em seus objetivos, dos outros migrantes que vieram na segunda metade do séc. XX, por causa da expansão da fronteira agrícola.

A atual etapa de ocupação da Amazônia ainda obedece às características dessa expansão agrícola, ou melhor, "rural" (pois a atividade preferencial é a pecuária extensiva). Os sujeitos dessa expansão são diversos, embora chame nossa atenção os migrantes oriundos das regiões Sul e Sudeste, entre eles sitiantes que vendem suas terras ou recebem ajuda financeira da família, para aventurarem-se nessa "terra de ninguém", que é a Amazônia, convertendo-se não raras vezes, em grandes latifundiários (ROCHA, 2006).

\footnotetext{
3 “Na época, a Amazônia era o único lugar do planeta que poderia atender ao dinâmico mercado nascente, pois só lá existiam seringueiras em quantidade suficiente para sustentar uma exploração em grande escala. Mas a existência da Hevea era apenas uma das condições para o estabelecimento do ciclo da borracha. Era necessário atrair capitais e mão-de-obra, que vieram em abundância. Do Nordeste migraram 300 mil "cearenses" entre 1860 e 1910; os capitais vieram dos fornecedores de produtos industrializados que eram consumidos nos seringais" (CASTRO, 2003, p. 46-47).
} 
A agroindústria não tem tido a mesma projeção na Amazônia, quando comparada ao Centro-Oeste, embora a soja esteja chegando para modificar sua paisagem, posto o grande interesse do governo federal por essa commodity. Para incentivar seu cultivo, hidrovias e ferrovias estão sendo construídas e outros projetos de infraestrutura estão em pauta (FEARNSIDE, 2000, p. 75). Aliás, os grandes projetos são uma constante para a região: a indústria de base, as hidrelétricas, a mineração, as ferrovias, tudo isso faz parte do ideário oficial - entra governo, sai governo - de desenvolvimento para a Amazônia. É necessário ressaltarmos essa circunstância: a imposição (que qualificamos como algo "de cima para baixo") atesta toda sua centralidade quando de sua atuação. Os projetos são grandes porque são "concentrados"; e são concentrados em razão da centralidade que os erigiu.

Existe também a questão geopolítica: a Hileia é a principal reserva (individualmente falando) de genoma no mundo, além de constituir um anteparo de equilíbrio climático fundamental para o planeta; dadas as dimensões e a posição cartográfica desse bioma. Os interesses de vários dos chamados "países desenvolvidos" sobre a Amazônia, que estão ficando cada vez mais explícitos, são há muito tempo conhecidos:

\begin{abstract}
A primeira investida neste sentido foi patrocinada pela UNESCO quando, em 1946, durante a primeira sessão de sua Conferência Geral, a agência instou seu DiretorGeral para que, em consonância com o governo brasileiro, tomasse todas as medidas necessárias para organizar uma conferência reunindo os países e organizações internacionais interessados em participar da criação de um instituto supranacional voltado para promover a investigação científica dos problemas amazônicos nas áreas da zoologia, botânica, fisiografia, agricultura e ciências sociais (antropologia, etnologia e educação). (QUEIROZ, 2012, p. 310)
\end{abstract}

Ao mesmo tempo, o governo brasileiro tem tido pouca sensibilidade no trato dessa questão, seja no confronto com os países estrangeiros, seja na relação com os habitantes locais.

Seria ingenuidade acreditar que uma potência como os Estados Unidos (por exemplo), cujos interesses na Região Amazônica datam de pelo menos meados do século XIX (QUEIROZ, 2012) voltará suas costas, espontaneamente, para esse imenso reservatório de $20 \%$ da água doce mundial (em superfície). O petróleo deve ter causado mais miséria que riqueza aos povos do Oriente Médio, desde que a Inglaterra começou a explorá-lo no séc. XIX. Se a água atravessar a mesma situação que atravessou o petróleo, nas próximas décadas o Brasil deverá ser alvo da política internacional de muitos países. O resultado desse "interesse" pode ser deduzido a partir de dois dos fatores indicados por Philippe Le Prestre (2000, p. 442), com relação às disputas por água doce: 1) o grau de vulnerabilidade e dependência de cada país com relação aos seus múltiplos usos; 2) os recursos de poder de que dispõem estes atores (na defesa e na ofensiva).

Além da água, precisamos lidar também com as ameaças ao chamado patrimônio genético - objeto das mais recentes revoluções das biociências. Do que se depreende que o desenvolvimento da Região Amazônica converteu-se, sobretudo, numa questão de segurança embora não o seja, exclusivamente - uma questão, portanto, nova e influenciada pelo contexto histórico.

Assim, retomamos a questão inicial: o planejamento (e a regionalização/di-visão) enquanto expediente para a proteção desse imenso patrimônio natural, ou melhor, sua defesa (defesa do patrimônio) como um projeto do Estado, projeto que deve ser empreendido na mesma proporção 
de seu valor estratégico. Nesse sentido, Brüseke (1996) nos chama a atenção para a complexidade da problemática "conservacionista". Uma vez que o estado não é uma entidade privada, mas, sobretudo no exemplo brasileiro, está orientado política e economicamente, na defesa do Sistema Capitalista - o qual nunca primou pela preservação de coisa alguma - a perspectiva se mostra no mínimo polêmica.

Portanto, é muito difícil imaginarmos que o discurso romântico dos ecologistas mais radicais possa se converter numa "prática política"; o que não significa que devemos reconhecer como inevitável a completa destruição dessa imensa floresta - e, aliás, é difícil acreditar que no atual contexto a comunidade internacional permitiria que assim o fizéssemos ${ }^{4}$. 0 objetivo aqui, não é negar a importância do ideário dos ecologistas, mas situar a problemática em seu verdadeiro âmbito: o "político".

Em pauta, nos dias atuais, uma proposta, aparentemente muito razoável, tem sido aquela do desenvolvimento sustentável. Seu sentido ainda é obscuro: "Não há [...] consenso quanto o significado desse conceito. Alguns autores acham que seu uso [...] pode estar sendo usado para ocultar conflitos e contradições, não solucionados pelo processo de modernização da Sociedade Ocidental" (DOS ANJOS, 2003, p.02). Porém, é possível apontarmos uma "noção comum", na qual o desenvolvimento econômico, da Amazônia, é pensado em moldes "artesanais", ou seja, é reconhecida a impossibilidade para se implantar o modelo norte-americano de industrialização/urbanização naquela área, cujos determinantes ecológicos, além de diferentes, são atualmente muito valorizados pela comunidade internacional; logo têm peso político. Esse "desenvolvimento econômico não-predatório", inclusive, responde aos anseios que o "Relatório Meadows", do Clube de Roma, desencadeou ao longo das últimas três décadas do século passado; anseios esses cujo título original daquele relatório explicitam bem: "Os limites do crescimento" 5 .

A princípio, causa um certo desconforto a ideia de manter a Região Amazônica nesse estágio "a-industrial", sobretudo porque a Zona Franca de Manaus foi um projeto de desenvolvimento que visava justamente industrializar a região. Entretanto, a Z.F.M. é um polo econômico e, mesmo considerando a capacidade de induzir o crescimento urbano/econômico do seu entorno, ela continua sendo apenas um fragmento da Região Amazônica. Mesmo que essa zona franca solucione os problemas do município de Manaus - e não estamos aqui admitindo que assim seja - a questão é bem mais complexa.

A dificuldade reside na concorrência do bioma com o modelo agro-econômico e não com o modelo industrial - ainda que a indústria, em si, pressuponha a destruição da vegetação nativa na

\footnotetext{
${ }^{4} \mathrm{O}$ Brasil, aliás, divide o bônus e o ônus do patrimônio amazônico com outros países sul-americanos. Circunstancia essa formalizada pela OTCA: "O Tratado de Cooperação Amazônica (TCA), assinado em julho de 1978 por Bolívia, Brasil, Colômbia, Equador, Guiana, Peru, Suriname e Venezuela, é o instrumento jurídico que reconhece a natureza transfronteiriça da Amazônia" (OTCA. Tratado de cooperação amazônica. Em: www.otca.info/portal/tratado-coopamazonica.php?p=otca, Acesso em: 20 março 2014).

5 “O objetivo do Clube de Roma, hoje uma ONG e na época uma organização informal, era examinar o complexo de problemas, que afligem os povos de todas as nações, [...]. A fase um do projeto sobre o dilema da humanidade concretizou-se, definitivamente, nos encontros mantidos no verão de 1970 em Berna, Suíça, e em Cambridge, Estado de Massachusetts [...]. O estudo da Fase Um foi dirigido por uma equipe internacional sob a direção do Prof. Dennis Meadows, com o apoio financeiro da Volkswagen Foundation. A equipe examinou os cinco fatores básicos que determinam e, por conseguinte, em última análise limitam o crescimento em nosso planeta - população, produção agrícola, recursos naturais, produção industrial e poluição. A pesquisa já está terminada. Este livro é o primeiro relato dos resultados, e é editado para o público em geral" (MEADOWS et AL., 1972, pp.11-12).
} 
área (específica) em que seja instalada. São as imensas pastagens $(100,200,300 \mathrm{~km} 2)$ ostentando baixíssimos índices de produtividade na pecuária, ou ainda os latifúndios com monocultura exportadora - sem que haja quase nenhum valor agregado - os verdadeiros adversários. Mas, igualmente, encontramos um adversário no "modo de vida" urbano-subdesenvolvido, mais nocivo para a (pretensa) identidade amazônica do que a substituição do extrativismo tradicional pelo assalariamento. Nesse sentido, a preservação do patrimônio natural está condicionada pela problemática (prévia) do desenvolvimento econômico - uma questão fartamente discutida, ao longo do séc. $\mathrm{XX}$, e não completamente equacionada.

Disso tudo resulta, a importância da chamada "sustentabilidade cultural" (DOS ANJOS, 2003, p. 04), a qual pressupõe um compromisso conjunto entre a sociedade civil e o estado. Compromisso esse, de manutenção do modo de vida tradicional - aliás, um patrimônio cultural amazônico - em razão da "sustentabilidade" inerente aos mesmos. Não se trata, nesse caso de impor um modelo em descompasso com a realidade de uma certa comunidade, tampouco de se desdobrar (o Estado) num esforço enorme de implantação e fiscalização de práticas ecologicamente corretas. É necessário muito menos: simplesmente o reconhecimento e valorização dos modos de vida sustentáveis (e tradicionais); em detrimento duma pecuária e duma agricultura predatórias.

Em todo caso, um projeto que encampasse essa perspectiva "primitivista" - com o perdão da palavra - é menos oneroso e com enorme potencial de legitimação por parte das pessoas. Além do mais, as outras tentativas (de desenvolvimento), das quais falamos, mesmo que brevemente, mostraram-se pouco eficazes. Talvez porque não levaram em conta o horizonte cultural da Amazônia? Difícil afirmar. Mas, nossa preocupação, quando utilizamos a expressão, ainda que controversa, "sustentabilidade", é justamente reconhecer o papel da cultura num mesmo patamar que o papel da economia, da ecologia e - claro - da política.

\section{CONSIDERAÇÕES FINAIS}

Do que foi dito até o momento, é preciso, finalmente, esboçarmos um esforço de síntese. De uma parte, permaneceu em aberto a questão do "regional"; de outra, causamos a impressão de que a proposta de sustentabilidade cultural prescinde de qualquer ação o estado.

Começando do fim, é importante reafirmarmos que a valorização dos modos de vida tradicionais não resulta imediatamente na adoção do "estado mínimo" liberalista, pois pressupõe, entre outras coisas, a solução de uma miríade de conflitos (sobretudo no campo) que apenas o estado tem discricionariedade para fazê-lo. Além do mais, os modos de vida tradicionais não devem ser obscurecidos pela falácia do "pré-histórico" - a má-fé ou ideia infundada de que a cultura dos "povos primitivos" é imutável. Até mesmo sociedades indígenas, atualmente, são reconhecidamente "históricas" - ainda que sem a escrita.

Enfim, é indispensável a presença do estado como elemento de integração (em suas instituições) no interior da floresta, sobretudo prestando assistência médica e levando a chamada "cultura escrita" através dos processos de alfabetização. Da mesma forma, no que tange à perspectiva geopolítica, a presença (ostensiva) do estado deve ser permanente.

É relativamente fácil comparar a perspectiva geopolítica e geoeconômica da "retirada" da floresta como forma de inserir - subordinadamente - a Região Amazônica, com uma perspectiva 
contemporânea de preservação da mesma floresta como forma de gerir essa região (de maneira realista inclusive) e percebermos qual o melhor caminho. Entretanto, é útil reconhecermos que a subordinação da Amazônia, frente a atores situados em outras escala (que não a regional), continuará se dando - não é outra a sua relação com o "Brasil" - e que a ideia (ou ideal) de autonomia se mostrará em perpétua tensão.

Conquanto esses atores não estejam norteados pela auferição de lucros - e há uma ameaça real ao patrimônio genético do bioma, ameaça essa capitaneada pelas multinacionais do setor farmacêutico ${ }^{6}$ - é perfeitamente razoável admitirmos as limitações da autonomia, impostas pelo regime político vigente (centralizador).

\section{REFERÊNCIAS BIBLIOGRÁFICAS}

1. BARRETO, A. Fortificações no Brasil - resumo histórico. Rio de Janeiro: Biblioteca do Exército Editora, 1958.

2. BERTALANFFY, L. Teoria geral dos sistemas. Tradução Francisco M. Guimarães. Petrópolis: Vozes, 1973.

3. BOURDIEU, P. O poder simbólico. Tradução Fernando Tomaz. 2. ed. Rio de Janeiro: Bertrand Brasil, 1998.

4. BRÜSEKE, F. J. Desestruturação e desenvolvimento. In: FERREIRA, L. C.; VIOLA, E. (orgs.) Incertezas de sustentabilidade na globalização. Campinas: Ed. da Unicamp, 1996.

5. CASTRO, M. H. M. Amazônia - soberania e desenvolvimento sustentável. Brasília: Confea, 2007.

6. CRUZ, N. R. "O diálogo entre o moderno e o antimoderno no discurso da Ação Integralista Brasileira". Estudos Ibero-Americanos, v. 37, n. 2, Porto Alegre, jul./dez. 2011, pp. 196-214.

7. DOS ANJOS, E. E. Desenvolvimento sustentável: "a insustentável leveza de ser", s/p. Revista Humanas. Espírito Santo: PGCHDR/CCHN/UFES. 2003. Disponível em: <www.revistahumanas.inf.br> Acessado em: 19 março 2014.

8. FEARNSIDE, P. M. 2000. "O avanço da soja como ameaça à biodiversidade na Amazônia", pp. 74-82. In: Anais do V Simpósio de Ecossistemas Brasileiros: Conservação, vol. I: Conservação e Duna. 2000. Vitória-ES: Universidade Federal de Espírito Santo. 477 p.

9. GOMES, P. C. C. O conceito de região e sua discussão. In: CASTRO, I. E.; GOMES, P. C. C.; CORRÊA, R. L. (org.) Geografia: Conceitos e temas. 6. ed. Rio de Janeiro: Bertrand Brasil, 2003.

10. HOBSBAWM, E. A era dos impérios. Tradução Sieni Maria Campos e Yolanda Steidel de Toledo. 8. ed. Rio de Janeiro: Paz e Terra, 2003.

11. KOSELLECK, R. Futuro passado: contribuição à semântica dos tempos históricos. Tradução Wilma Patrícia Maas e Carlos Almeida Pereira. Rio de Janeiro: Contraponto: Ed. PUC-Rio, 2006.

12. LE PRESTRE, P. Ecopolítica Internacional. Tradução Jacob Gorender. São Paulo: Senac, 2000.

13. MEADOWS, D. L.; MEADOWS, D. H.; RANDERS, J.; BEHRENS, W. W. Limites do crescimento -

6 “[...] o rol exemplificativo da Biopirataria é largo, podendo-se fazer referência aos episódios abarcando a Castanhado-Pará, a Ayahuasca (principal planta empregada nos rituais do Santo Daime), a Espinheira-Santa, a Unha-de-Gato, a Vacina do Sapo, dentre muitos outros" (PANCHERI, 2013, p. 445). 
um relatório para o Projeto do Clube de Roma sobre o dilema da humanidade. São Paulo: Ed. Perspectiva, 1972.

14. PANCHERI, I. "Biopirataria: reflexões sobre um tipo penal”. Rev. Fac. Dir. Univ. São Paulo, v. 18, São Paulo, jan./dez. 2013, pp. 443-487.

15. PRADO JUNIOR, C. Formação do Brasil contemporâneo. 20. ed. São Paulo: Editora Brasiliense, 1996.

16. História econômica do Brasil. 43. ed. São Paulo: Brasiliense, 1998.

17. QUEIROZ, F. A. Hidropolítica e segurança: as bacias platina e amazônica em perspectiva comparada. Brasília: FUNAG, 2012.

18. ROCHA, B. N. "Em qualquer chão: sempre gaúcho!": a multiterritorialidade do migrante "gaúcho" no Mato Grosso. 2006. 157 f. Dissertação (Mestrado). Universidade Federal Rural do Rio de Janeiro. Seropédica-RJ, 2006. 